\title{
Oculomotor Executive Dysfunction During the Early and Later Stages of Sport-Related Concussion Recovery
}

Brandon Webb, The University of Western Ontario

Supervisor: Heath, Matthew, The University of Western Ontario

A thesis submitted in partial fulfillment of the requirements for the Master of Science degree in Kinesiology

(c) Brandon Webb 2017

Follow this and additional works at: https://ir.lib.uwo.ca/etd

Part of the Cognitive Neuroscience Commons

\section{Recommended Citation}

Webb, Brandon, "Oculomotor Executive Dysfunction During the Early and Later Stages of Sport-Related Concussion Recovery" (2017). Electronic Thesis and Dissertation Repository. 5016.

https://ir.lib.uwo.ca/etd/5016

This Dissertation/Thesis is brought to you for free and open access by Scholarship@Western. It has been accepted for inclusion in Electronic Thesis and Dissertation Repository by an authorized administrator of Scholarship@Western. For more information, please contact wlswadmin@uwo.ca. 


\begin{abstract}
Executive dysfunction represents a persistent concussion deficit; however, it is largely unclear whether the deficit persists in an athlete after they have been deemed safe to return to play. In the present work, athletes with a sport-related concussion, and their age- and sex-matched controls, completed prosaccades and executive-related antisaccades: (1) 2-6 days post-concussion (i.e., initial assessment), and (2) 14-20 days after initial assessment and only when an athlete was medically cleared for safe return to play (i.e., follow-up assessment). Initial assessment antisaccades for the concussed group produced longer reaction times (RT) and more directional errors than the control group. The follow-up assessment showed comparable between-group antisaccade RTs; however, the concussed group exhibited more directional errors. Thus, the antisaccade task detects executive-related concussive deficits in both the early and later stages of concussion recovery.
\end{abstract}

Keywords: antisaccade, concussion, executive control, prosaccade, oculomotor 


\section{Co-Authorship Statement}

The author, under the supervision and mentorship of Dr. Matthew Heath and Dave Humphreys, conducted the work in this master's thesis. Dave Humphreys provided valued guidance during conceptualization of this project and participant recruitment, and Dr. Matthew Heath provided valued guidance during conceptualization of this project, participant recruitment, data collection, data analyses and interpretation, and manuscript writing. 


\section{Acknowledgments}

I am grateful to my participants for their involvement in this project, and the FowlerKennedy Sport Medicine Clinic, London, ON, for their assistance with participant recruitment.

I would also like to provide a special thank you to my graduate supervisor, Dr. Matthew Heath. You are an inspiration to your students and to those looking to pursue a future in academia. Your passion and support was crucial to my development throughout my masters and your constant guidance and encouragement kept me on track toward success. I am sincerely grateful for your mentorship.

Further, I would like to thank my lab mates, friends, and family for being there every step of the way. All the love and support that you have given me in every aspect of life has helped me believe that I can achieve anything I set my mind to.

Lastly, a very special thank you to my mom. I have always done my best to make you proud, and in turn, out of everyone who has taught me a lesson along the way, you have taught me the most important one. You have shown me that giving up is never the answer and if you want something bad enough you go out and get it. You have taught me to always have passion, give everything I've got, and be inspiring - especially to those you love and care about. You'll never know how much your support has meant to me. I dedicate this work to you. 


\section{Table of Contents}

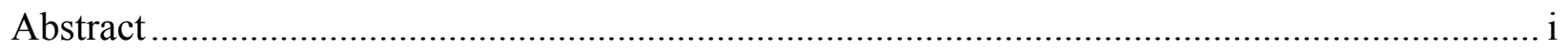

Co-Authorship Statement................................................................................................ ii

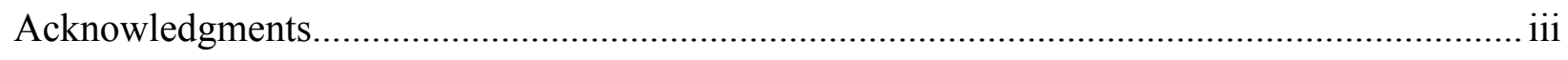

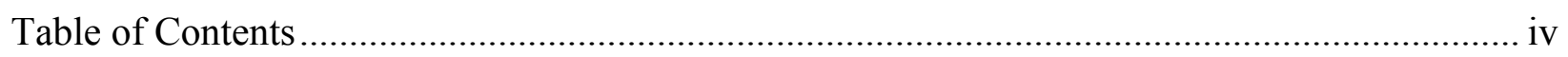

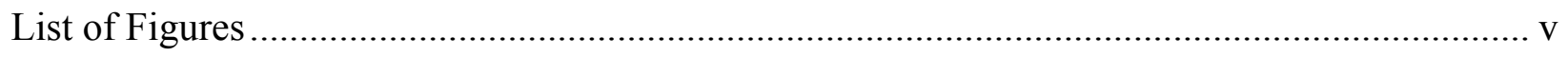

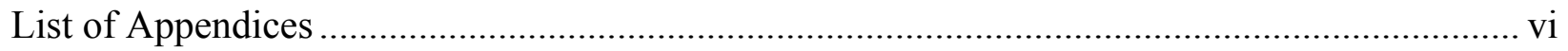

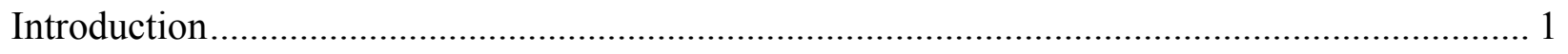

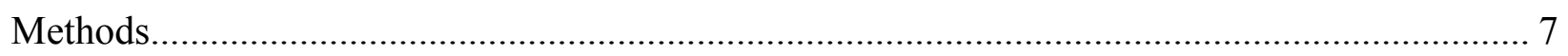

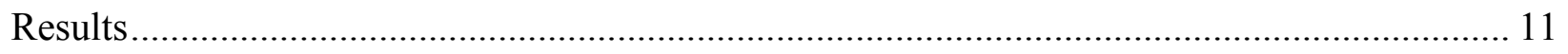

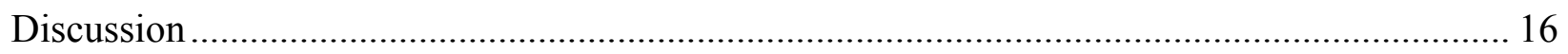

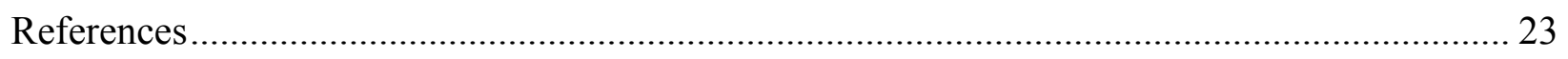

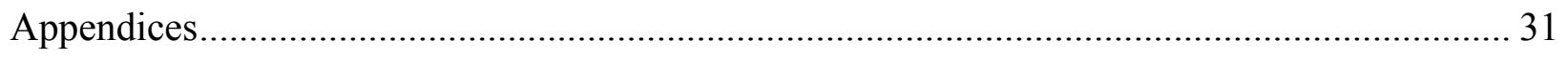

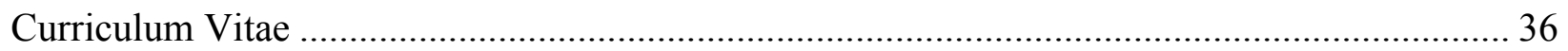




\section{List of Figures}

Figure 1. The large main panels show pro- and antisaccade reaction times (RT: ms) for individual participants in the control and concussed groups at initial and follow-up assessments. The smaller offset panels show group mean pro- and antisaccade RTs for control and concussed groups at initial and follow-up assessments and errors bars represents 95\% between-participant confidence intervals.

Figure 2. The large main panels show the percentage of pro- and antisaccade directional errors for individual participants in the control and concussed groups at initial and follow-up assessments. The smaller offset panels show group mean pro- and antisaccade directional errors for control and concussed groups at initial and follow-up assessments and errors bars represents 95\% between-participant confidence intervals.

Figure 3. Mean pro- and antisaccade gains for control and concussed groups at initial and followup assessments and errors bars represents 95\% between-participant confidence intervals

Figure 4. Mean RTs (see left panel) and amplitude gains (see right panel) for pro- and antisaccade directional error trials and errors bars represents $95 \%$ between-participant confidence intervals 19 


\section{List of Appendices}

Appendix A: Health Sciences Research Ethics Board Approval............................................ 31

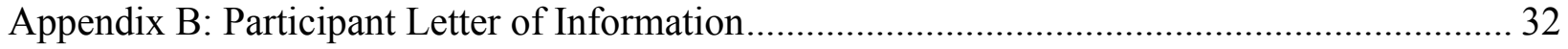

Appendix C: Participant Consent Form .......................................................................... 35 


\section{Introduction}

A sport-related concussion is a mild traumatic brain injury (mTBI) arising from biomechanical forces to the head, face, neck - or elsewhere on the body - that are transmitted to the brain and result in a functional disturbance to the brain's neural and glial networks (McCrory et al., 2013; for review see Meaney \& Smith, 2011). The Centers for Disease Control and Prevention estimates that 1.6 to 3.8 million concussions occur annually in the United States (Langlois, Rutland-Brown, \& Wald, 2006) and the Canadian Institute for Health Information reports that sport-related concussions are the third leading cause of hospital admissions among mTBI and traumatic brain injuries (TBI) in Canada (Gessel, Fields, Collins, Dick, \& Comstock, 2007). Of those individuals diagnosed with a concussion in any given year, approximately 225,000 show long-term cognitive deficits that negatively impact their educational, occupational and leisure activities (Preiss-Farzanegan, Chapman, Wong, Wu, \& Bazarian, 2009). Moreover, individuals diagnosed with a sport-related concussion are three times more likely to sustain a subsequent and more severe concussion upon their return to play (Nordström, Edin, Lindström, \& Nordström, 2013). As a result, there is continued need for research aimed at improving concussion diagnosis and determining when an athlete can safely return to play.

The Sport Concussion Assessment Tool (ver 3.0: i.e., SCAT3) and the Child-SCAT3 (ages 5-12) is a valid and commonly used neuropsychological battery that has shown to provide a reliable sideline tool - when administered by an experienced clinician - for differentiating between the cognitive-motor abilities of concussed and non-concussed athletes (McCrory et al., 2013). The SCAT3 assesses concussive signs and symptoms including: somatic, cognitive, emotional, physical, and behavioural components. The recently published Consensus Statement 
on Concussion in Sport states that the SCAT's ability to reliably differentiate between concussed and non-concussed athletes decreases significantly from three to five days after the concussive event (McCrory et al., 2017). As such, the timely report of a possible concussive event and subsequent administration of the SCAT is essential for a valid assessment; however, it is important to recognize that many sport venues (i.e., recreational and youth sport) do not provide the opportunity for a timely SCAT assessment. Further, many athletes do not immediately selfreport a possible concussive event (Harmon et al., 2013). Accordingly, several studies have focused on lab-based measures of cognitive-motor abilities to identify the nature and severity of concussive dysfunction. The dual-task effect on gait and balance is a common technique that has been used to examine concussed versus non-concussed athletes (Howell, Osternig, \& Chou, 2013; Catena, van Donkelaar, \& Chou, 2007; Fait, Swaine, Cantin, Leblond, \& McFadyen, 2013; Teel, Register-Mihalik, Blackburn, \& Guskiewicz, 2013). For example, Howell et al. (2013) had participants identified with a concussion and their age-matched controls walk at their preferred speed in single- and dual-task conditions. The single-task condition entailed walking on a treadmill without a secondary task, whereas that dual-task condition involved walking and performing the Stroop task. For the Stroop task, participants heard either the word "low" or "high" spoken in a low or high tone and were required to report the "same" (i.e., standard) or opposite (i.e., non-standard) tone the word was spoken in. In other words, in the non-standard condition participants were required to ignore the standard meaning of the word and instead report a non-standard attribute attached to the word. Single- and dual-task performance was completed 72 hours post-concussion, as well as one- and two-weeks, and one- and two-months post-concussion. The concussed group yielded slower average walking speeds and more errorful performance on the Stroop task compared to their age-matched controls, and this result was 
observed across the two-month assessment period. Thus, the authors proposed that dual-task gait studies can effectively assess long-term dysfunctions to cognitive, attentional, motor, and sensory functioning in individuals who have experienced a concussion.

Although dual-task gait assessments show promise in identifying concussive deficits, the task requires a sizeable area for testing (i.e., long walkway or a treadmill), and the recording of gait kinematics (i.e., affixing retro-reflective or infrared markers to the participant) can require a considerable set-up time. Further, dual-task gait assessments measure a wide-range of cognitive (i.e., attentional, conflict monitoring, executive control and visuospatial analyses), motor, and sensory processes, and therefore do not address specific sensorimotor and/or cognitive dysfunction arising from a concussion. Accordingly, my study employed a task requiring: (1) a brief administration period, and (2) a selective examination of executive function. First, a brief administration period (i.e., $<10$ minutes) was deemed imperative because cognitive-demanding tasks during the acute stage of recovery can heighten concussive symptoms (e.g., headache, confusion, dizziness, nausea, fatigue, and vertigo), and therefore decrease performance (Ledoux et al., 2017). Second, executive dysfunction is a hallmark feature of persons with a TBI (i.e., a group frequently linked to car accidents or traumatic falls) and represents the most persistent deficit impairing recovery (Lezak, 1982; McDonald, Flashman, \& Saykin, 2002). Broadly defined, executive control relates to the planning and control of volitional action, processing of single and multiple stimuli, updating and monitoring of working memory, and asserting highlevel inhibitory control (Norman \& Shallice 1986; Welsh, Pennington, \& Groisser, 1991). Although persons with a TBI frequently demonstrate normative data on general measures of intellectual ability, such persons exhibit selective deficits on executive-related tasks (Brooks, Fos, Greve, \& Hammond, 1999). It is therefore possible that an executive task may provide the 
requisite resolution and ease of administration to detect subtle deficits associated with the acute and later stages of concussion recovery.

Antisaccades are an executive-related oculomotor task requiring that an individual saccade mirror-symmetrical to a target stimulus. Antisaccades have longer reaction times (RT), increased directional errors (Hallett, 1978; Fischer \& Weber, 1992), and less accurate and more variable amplitudes (Dafoe, Armstrong, \& Munoz, 2007; Gillen \& Heath, 2014a; b) than saccades directed toward a veridical target location (i.e., prosaccade). The behavioural 'costs' associated with antisaccades have been tied to a two-component process involving: (1) the suppression of a pre-potent stimulus-driven prosaccade (i.e., response suppression) and, (2) the $180^{\circ}$ inversion of a target's spatial coordinates (i.e., vector inversion) (for review see Munoz \& Everling, 2004). Neuroimaging studies have shown that directionally correct antisaccades are linked to increased activation of neural networks within the prefrontal cortex and lateral intraparietal area (i.e., frontoparietal network) - areas known to support executive control (Everling \& Johnston, 2013). For example, an fMRI study found that the preparatory phase of an antisaccade was correlated with increased levels of activation in classic saccade networks (i.e., frontal eye field, supplementary eye field, and lateral intraparietal area), dorsolateral prefrontal cortex, and anterior cingulate cortex (Brown, Vilis, \& Everling, 2007; see also Curtis \& D’Esposito, 2003; DeSouza, Menon, \& Everling, 2002; Ford, Goltz, Brown, \& Everling, 2005), as well as a respective increase and decrease in the activity of collicular fixation and saccade build-up neurons (Everling, Paré, Dorris, \& Munoz, 1998; Everling, Dorris, Klein, \& Munoz, 1999). In the clinical neuropsychology, antisaccade performance has been shown to reliably differentiate individuals with prodromal Alzheimer's disease (Kaufman, Pratt, Levine, \& Black, 2012; Heath, Weiler, Gregory, Gill, \& Petrella, 2016; Heath, Shellington, Titheridge, Gill, \& 
Petrella, 2017), identify individuals with frontal lobe lesions (Guitton, Buchtel, \& Douglas, 1985; Pierrot-Deseilligny, Rivaud, Gaymard, \& Agid, 1991), and evaluate schizotypal symptom control (Macare, Wöstmann, Aichert, Meindl, \& Ettinger, 2014; Wan, Thomas, Pisipati, Jarvis, $\&$ Boutros, 2017). Further, and what is most germane to the present work, persons diagnosed with non-sport-related mTBI and TBIs exhibit longer antisaccade RTs and produce more directional errors than their age-matched controls when evaluated 7 years following their injury (Kraus et al., 2007). These findings, coupled with the brief administration of antisaccades, and their hands- and language-free nature, make it an ideal tool for identifying a concussed athlete and determining when they may safely return to play.

To my knowledge, only one purpose-designed study has previously examined the use of antisaccades in otherwise healthy young adults with a sport-related concussion. Johnson, Zhang, Hallett, and Slobounov (2015a; see also Johnson, Hallet, \& Slobounov, 2015b) examined the concurrent behavioural data and fMRI measures of antisaccades in nine concussed athletes as well as nine age- and sex-matched controls at initial (i.e., $<7$ days post-injury) and follow-up (i.e., 30 days post-injury) assessments. Behavioural data indicated that the concussed group had antisaccade RTs that were $40 \mathrm{~ms}$ and $19 \mathrm{~ms}$ longer than the control group at initial and follow-up assessments, respectively, and that the concussed group demonstrated increased antisaccade directional errors at both time points. Further, initial assessment fMRI data showed that the concussed group exhibited a range of hypo- and hyperactivity across a range of cortical and subcortical structures. At follow-up assessment, the fMRI findings for control and concussed athletes did not reliably differ. As a result, Johnson et al. (2015a; b) concluded that oculomotor testing (i.e., antisaccades) shows potential as an assessment and management tool for detecting a concussion and monitoring recovery of function. 
The present work compared antisaccade performance in individuals identified with a sport-related concussion to their age- and sex-matched controls at initial and follow-up assessments. The initial assessment occurred within 2-6 days of a concussive event and the follow-up assessment occurred 14-20 days after initial assessment and was completed only after participants were provided with medical clearance for safe return to play. Notably, my work differs from Johnson et al.'s (2015a; b) in three main respects. First, my study measured pro- and antisaccade performance without the concurrent measure of brain activity via fMRI. This allowed for a brief (i.e., $<10$ minutes) oculomotor assessment designed to limit the onset of concussive symptoms associated with sustained cognitive activity. Second, my work included the use of prosaccades as a natural control to antisaccades because such actions are mediated via direct retinotopic motor maps in the superior colliculus (Wurtz \& Albano, 1980) that operate largely independent of any top-down executive control (Pierrot-Deseilligny et al., 1991). Importantly, if there is no deficit to prosaccade performance, this would demonstrate that concussions elicit an executive-specific - as opposed to general - oculomotor dysfunction. Third, the current follow-up assessment occurred immediately after (i.e., on the same day) the SCAT3 and clinical evidence indicated the athlete could safely return to play. Given this manipulation, my work provided a framework to determine if subtle executive impairments persist even after an athlete is cleared for a safe return to play. In terms of research predictions, if a concussion selectively impacts executive control, then antisaccade (but not prosaccade) RTs should be longer and elicit more directional errors in the concussed than the control group at the initial assessment. Further, if antisaccades provide a reliable indication of concussion recovery then performance at the follow-up assessment should be comparable across concussed and control groups. 


\section{Methods}

\section{Participants}

Fifteen participants identified with a sport-related concussion (i.e., concussed group, age range: 21-26 years; 11 males, 4 females) were recruited through the Sport Medicine Concussion Care Program at the local Fowler-Kennedy Sport Medicine Clinic in London, ON, CA. Participants attended this program within 2-6 days of a possible concussive event and were diagnosed with a concussion via the SCAT3 and combined clinical judgments of a sports physician and/or physiotherapist. In addition, fifteen healthy individuals from the Western University community were recruited as age- and sex-matched controls. Inclusion criteria for the control group was normal or corrected-to-normal vision and right hand dominance as determined by a modified version of the Waterloo Handedness questionnaire (Bryden, 1977). Only righthanded participants were included here because such a population has a more homogenous brain organization than their left-handed counterparts. Exclusion criteria for the control group entailed a previous or current neurological or neuropsychiatric deficit (including a concussion), attention deficit hyperactivity disorder, or a documented learning impairment. The same criteria were used for the concussed group aside from their current concussion. Because multiple concussions can exhibit more severe and long-term deficits than a single concussion (Thériault, Beaumont, Tremblay, Lassonde, \& Jolicoeur, 2011), only those athletes that self-reported no previous concussion history were included. Prior to data collection, all participants signed consent forms approved by the Health Sciences Research Ethics Board, University of Western Ontario, and this work was conducted in accordance with the ethical standards laid down in the Declaration of Helsinki. 


\section{Initial and follow-up oculomotor assessment}

The concussion group completed their oculomotor assessment (see details below) at two different times (i.e., initial and follow-up). The initial assessment occurred 2-6 days after the concussive event (average $=4.2$ days, $\mathrm{SD}=1.2$ ), and in all cases occurred within 24 hours of the clinical assessment. The follow-up assessment occurred 14-20 days after the initial assessment (average $=16.4$ days, $\mathrm{SD}=1.7$ ) and at this time all participants self-reported that they were deemed fit for a safe return to play as per the Sport Medicine Concussion Care Program guidelines at the local Fowler-Kennedy Sport Medicine Clinic (i.e., a follow-up SCAT3 and the clinical judgment of a sports physician and/or physiotherapist). Further, the follow-up assessment was generally completed within 2-hours of participants seeing the Fowler-Kennedy clinical care team. For the control group, the duration between initial and follow-up assessments was designed to match as closely as possible the timing of their age- and sex-matched participant in the concussion group (average $=15.6$ days, $\mathrm{SD}=1.6$ )

\section{Apparatus and procedures for oculomotor assessment}

Participants sat comfortably in a height-adjustable chair located in front of a tabletop (height $775 \mathrm{~mm}$ ) with their head placed in a head-chin rest. Visual stimuli were presented on a 690 by $470 \mathrm{~mm}$ stimulus board placed on the tabletop $550 \mathrm{~mm}$ from the participant and centered on their midline. The board contained a series of LEDs (luminance $=48 \mathrm{~cd} / \mathrm{m}^{2}$ ) covered with black stereo cloth. A multi-coloured LED located at the center of the stimulus board and at the eye level of the participant served as the fixation, whereas yellow LEDs located $15.5^{\circ}$ (i.e., proximal target) and $20.5^{\circ}$ (i.e., distal target) left and right of the fixation, in the same horizontal meridian as the fixation, served as target stimuli. The different target eccentricities were used to 
prevent participants from adopting a stereotyped response from trial-to-trial. The gaze location of participants' left eye was measured via a video-based eye-tracking system (Eye-Trac6, Applied Sciences Laboratories, Bedford, MA) sampling at $360 \mathrm{~Hz}$. Prior to data collection a nine-point calibration of the participants' viewing space was completed and confirmed via an immediate follow-up calibration $\left(<1^{\circ}\right.$ for any calibration point). Two monitors visible only to the experimenter provided: (1) real-time point of gaze location, (2) trial-by-trial saccade kinematics (e.g., displacement and velocity), and (3) information regarding the accuracy of the eye tracking system (e.g., to recalibrate if necessary). The presentation of visual stimuli and all computer events were controlled via MATLAB (7.6; The MathWorks, Natick, MA) and the Psychophysics Toolbox extensions (ver. 3.0; see Brainard 1997). The lights in the experimental suite were extinguished during data collection and background noise was less than $36 \mathrm{~dB}_{\mathrm{A}}$.

A trial began with illumination of the fixation point to a green (i.e., prosaccade) or a red (i.e., antisaccade) colour and informed participants to direct their gaze to its location. Once a stable gaze was achieved (i.e., $\pm 1.5^{\circ}$ for $500 \mathrm{~ms}$ ), a randomized foreperiod was initiated (i.e., $1,000-2,000 \mathrm{~ms}$ ) after which one of the four target stimuli appeared for $50 \mathrm{~ms}$. The $50 \mathrm{~ms}$ target presentation used here was designed to equate pro- and antisaccades for the absence of extraretinal feedback (e.g., Heath, Weiler, Marriott, \& Welsh, 2011). The fixation point remained visible during the foreperiod and was extinguished coincident with offset of the target stimulus (i.e., overlap paradigm). The onset of the target stimulus signaled participants to pro(i.e., saccade to the target) or antisaccade (i.e., saccade mirror-symmetrical to the target) "as quickly and accurately" as possible. Pro- and antisaccades were performed in separate and randomly ordered blocks, and within each block the combination of target eccentricity (i.e., proximal and distal) and visual field (i.e., left and right space) was presented on 10 trials. Thus, 
40 pro- and 40 antisaccade trials were performed at each of the initial and follow-up oculomotor assessments (i.e., 160 total experimental trials). Data collection (including separate calibrations for pro- and antisaccade blocks) required less than 10 minutes.

\section{Data reduction, dependent variables and statistical analysis}

Displacement data were filtered offline using a dual-pass Butterworth filter with a lowpass cut-off frequency of $15 \mathrm{~Hz}$. Data were differentiated via a five-point central finite algorithm to compute instantaneous velocities. Accelerations were similarly obtained from the velocity. Saccade onset was determined when velocity and acceleration values exceeded $30 \%$ and $8,000^{\circ} / \mathrm{s}^{2}$, respectively. Saccade offset was determined when velocity fell below $30^{\circ} / \mathrm{s}$ for 15 consecutive frames (i.e., $42 \mathrm{~ms}$ ).

Dependent variables included reaction time (RT: time between target onset and saccade onset), the coefficient of variation (CV) of RT (standard deviation/mean $\times 100 \%$ ), the percentage of directional errors (i.e., a prosaccade instead of an instructed antisaccade or vice versa), and amplitude gain (i.e., saccade amplitude/target amplitude) in the primary (i.e., horizontal) movement direction. Trials were removed for signal loss (i.e., eye-blink), an RT less than 100 ms (i.e., an anticipatory or express saccade) (Wenban-Smith \& Findlay, 1991), or an amplitude less than $2^{\circ}$ or greater than $26^{\circ}$ (Gillen \& Heath 2014a; b). Less than $8 \%$ of trials were excluded based on the aforementioned criteria. Trials with a directional error were excluded from the general analyses of RT and amplitude gains because trials with an antisaccade directional error are mediated via planning mechanisms distinct from their directionally correct counterparts (DeSimone, Weiler, Aber, \& Heath, 2014). Further, for each group by time by task cell, every participant successfully completed at least 15 trials that were used in the generation of their 
means. Dependent variables were examined via 2 (group: concussed, control) by 2 (time: initial, follow-up assessment) by 2 (task: pro-, antisaccade) split-plot ANOVAs.

\section{Results}

Kinematic Variables

Reaction time (RT) and coefficient of variation (CV of RT)

RT yielded main effects of group, $F(1,28)=109.12, \mathrm{p}<0.001, \eta_{\mathrm{p}}{ }^{2}=0.79$, time,

$\mathrm{F}(1,28)=311.25, \mathrm{p}<0.001, \eta_{\mathrm{p}}{ }^{2}=0.91$, and task, $\mathrm{F}(1,28)=874.14 \mathrm{p}<0.001, \eta_{\mathrm{p}}{ }^{2}=0.96$, as well as interactions involving group by time, $\mathrm{F}(1,28)=23.34, \mathrm{p}<0.001, \eta_{\mathrm{p}}{ }^{2}=0.45$, group by task, $\mathrm{F}(1,28)=48.42, \mathrm{p}<0.001, \eta_{\mathrm{p}}{ }^{2}=0.63$, and group by time by task, $\mathrm{F}(1,28)=83.87, \mathrm{p}<0.001$, $\eta_{\mathrm{p}}{ }^{2}=0.75$. As expected, prosaccade RTs were always shorter than antisaccade RTs. In decomposing the three-way interaction, Figure 1 shows that prosaccade RTs did not reliably differ between the concussed and control groups at either the initial $(\mathrm{t}(28)=-1.75, \mathrm{p}=0.09)$ or follow-up $(\mathrm{t}(28)=1.23, \mathrm{p}=0.23)$ assessment. In contrast, antisaccade RTs for the concussed group were longer than the control group at the initial assessment $(\mathrm{t}(28)=13.68, \mathrm{p}<0.001)$, however, the concussed and control groups did not reliably differ at the follow-up assessment $(t(28)=0.16, p=0.88)$. 


\section{Initial Assessment}

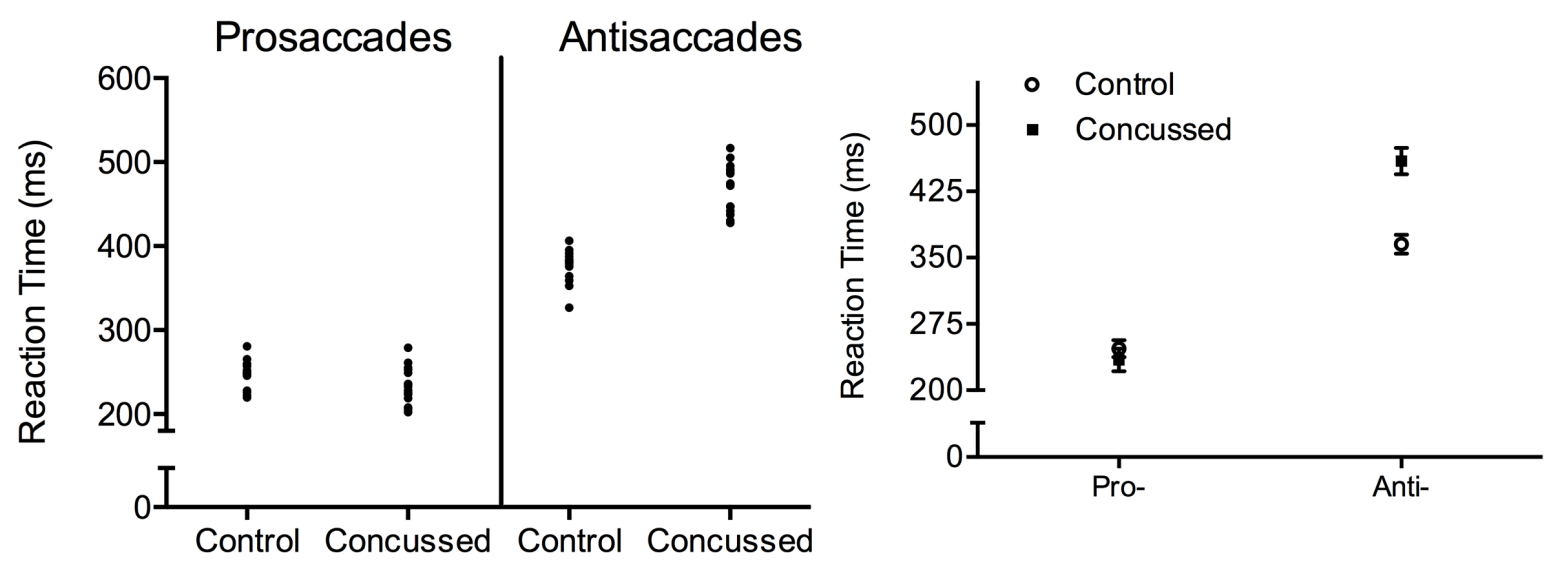

Follow-up Assessment

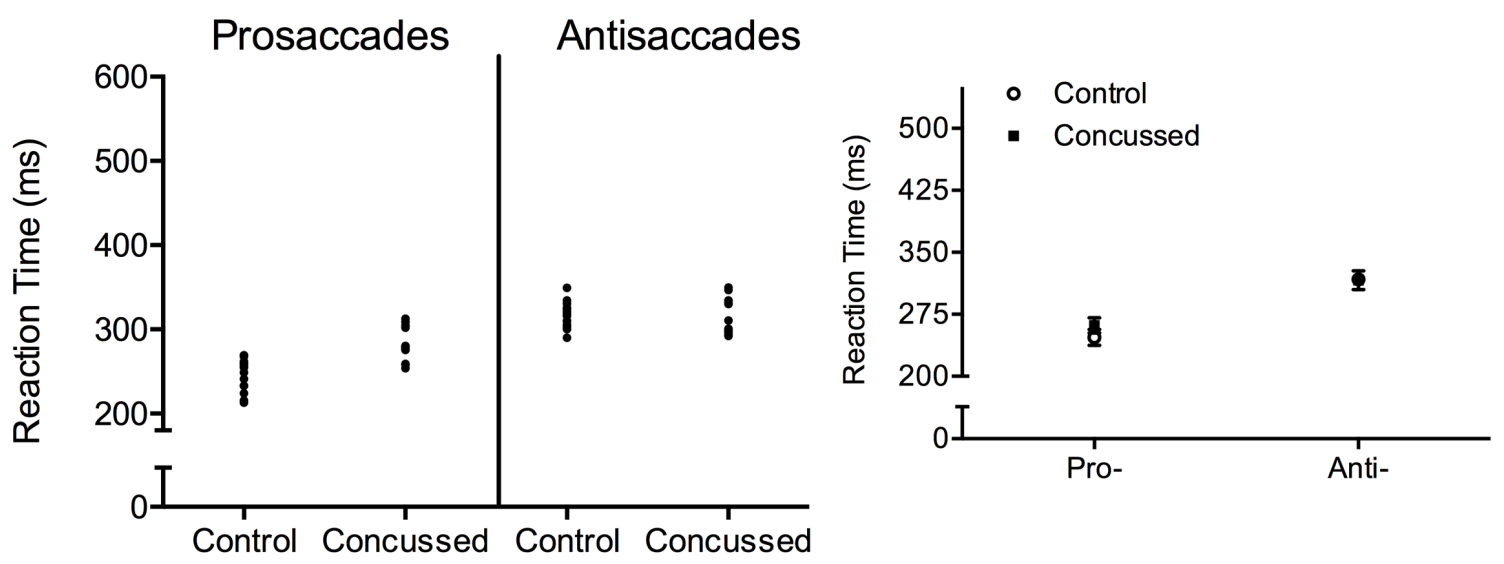

Figure 1. The large main panels show pro- and antisaccade reaction times (RT: ms) for individual participants in the control and concussed groups at initial (top panel) and follow-up (bottom panel) assessments. The individual participant values demonstrate that initial assessment antisaccade RTs for each participant in the concussed group were longer than any participant in the control group. The smaller offset panels show group mean pro- and antisaccade RTs for control and concussed groups at initial and follow-up assessments. Error bars represent 95\% between-participant confidence intervals (Cumming, 2013). Note: the data shown here relate only to directionally correct pro- and antisaccades. 
The CV of RT revealed main effects of time, $\mathrm{F}(1,28)=30.96, \mathrm{p}<0.001, \eta_{\mathrm{p}}{ }^{2}=0.52$, task, $\mathrm{F}(1,28)=109.78, \mathrm{p}<0.001, \eta_{\mathrm{p}}{ }^{2}=0.80$, and an interaction involving group by time, $\mathrm{F}(1,28)=60.27$, $\mathrm{p}<0.001, \eta_{\mathrm{p}}{ }^{2}=0.69$. Values for prosaccades $(23, \mathrm{SD}=3)$ were larger than antisaccades $(15$, $\mathrm{SD}=2$ ). The group by time interaction indicated that initial assessment values were larger for the concussed $(24, \mathrm{SD}=4)$ than the control $(17, \mathrm{SD}=4)$ group $(\mathrm{t}(28)=5.12, \mathrm{p}<0.001)$, whereas, at the follow-up assessment, values were smaller for the concussed $(14, \mathrm{SD}=1)$ than the control $(19$, $\mathrm{SD}=2)$ group $(\mathrm{t}(28)=-7.00, \mathrm{p}<0.001)$.

\section{Directional errors}

Directional errors yielded significant main effects of group, $F(1,28)=38.00, p<0.001, \eta_{p}{ }^{2}$ $=0.58$, time, $\mathrm{F}(1,28)=11.11, \mathrm{p}<0.01, \eta_{\mathrm{p}}{ }^{2}=0.28$, and task, $\mathrm{F}(1,28)=21.15, \mathrm{p}<0.001, \eta_{\mathrm{p}}{ }^{2}=0.43$, and interactions involving group by time, $\mathrm{F}(1,28)=12.30, \mathrm{p}<0.01, \eta_{\mathrm{p}}{ }^{2}=0.30$, time by task, $\mathrm{F}(1,29)=6.83, \mathrm{p}<0.02, \eta_{\mathrm{p}}{ }^{2}=0.19$, and group by time by task, $\mathrm{F}(1,28)=9.41, \mathrm{p}<0.01, \eta_{\mathrm{p}}{ }^{2}=0.25$. As expected, prosaccades $(9 \%, \mathrm{SD}=8)$ were associated with fewer directional errors than antisaccades $(20 \%, \mathrm{SD}=11)$ across all experimental manipulations. In breaking down the threeway interaction, I first computed between-group comparisons of pro- and antisaccades at initial and follow-up assessments. Figure 2 shows that the concussed group produced more pro- and antisaccade directional errors than the control group at initial and follow-up assessment (all $\left.t(28)>2.10, \mathrm{ps}^{2}<0.05\right)$. Thus, the between-groups comparison did not uncover the nature of the interaction. Accordingly, I computed within-group comparisons and found that the control group's pro- $(6 \%, \mathrm{SD}=5)$ and antisaccade $(13 \%, \mathrm{SD}=6)$ directional errors at time of their initial assessment did not reliably differ from their pro- $(5 \%, \mathrm{SD}=4)$ and antisaccade $(14 \%, \mathrm{SD}=5)$ directional errors at time of their follow-up assessment (all $\mathrm{t}(14)=0.16$ and $-0.30, \mathrm{ps}=0.87$ and 
0.76 , respectively). In terms of the concussed group, prosaccade directional errors did not reliably differ between initial $(13 \%, \mathrm{SD}=11)$ and follow-up $(11 \%, \mathrm{SD}=8)$ assessments $(\mathrm{t}(14)=1.44, \mathrm{p}=0.17)$; however, antisaccade directional errors decreased from the initial $(34 \%$, $\mathrm{SD}=18)$ to the follow-up $(19 \%, \mathrm{SD}=7)$ assessment $(\mathrm{t}(14)=4.50, \mathrm{p}<0.001)$.

\section{Initial Assessment}

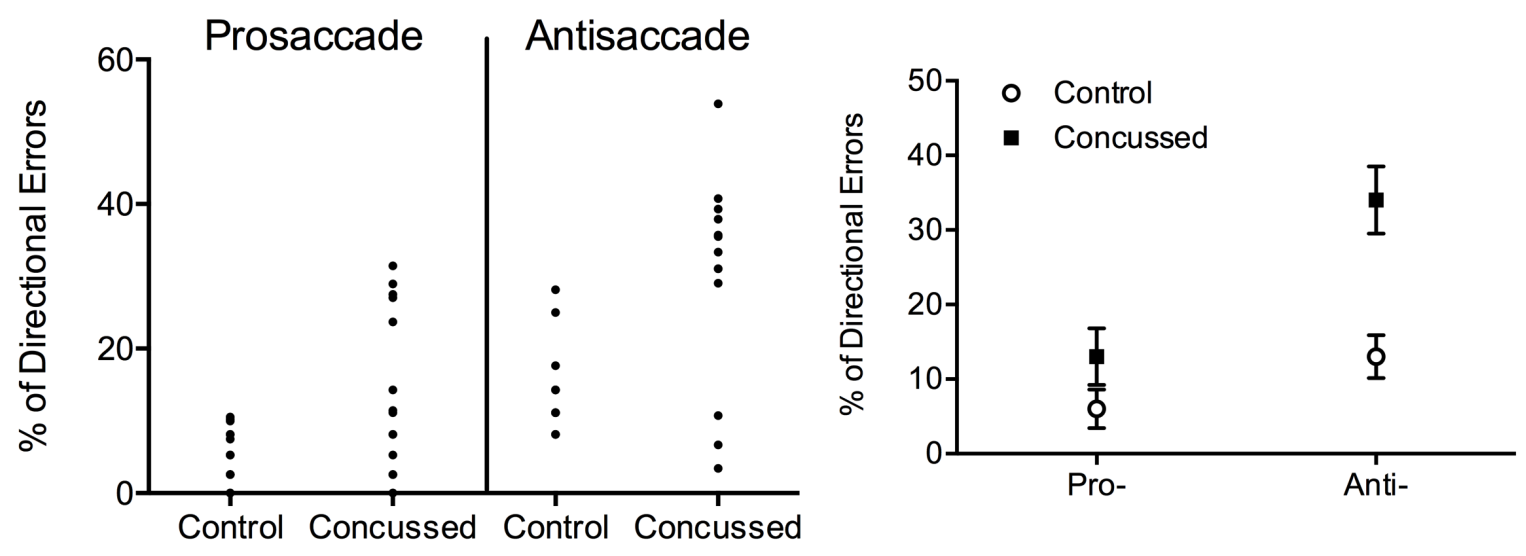

Follow-up Assessment

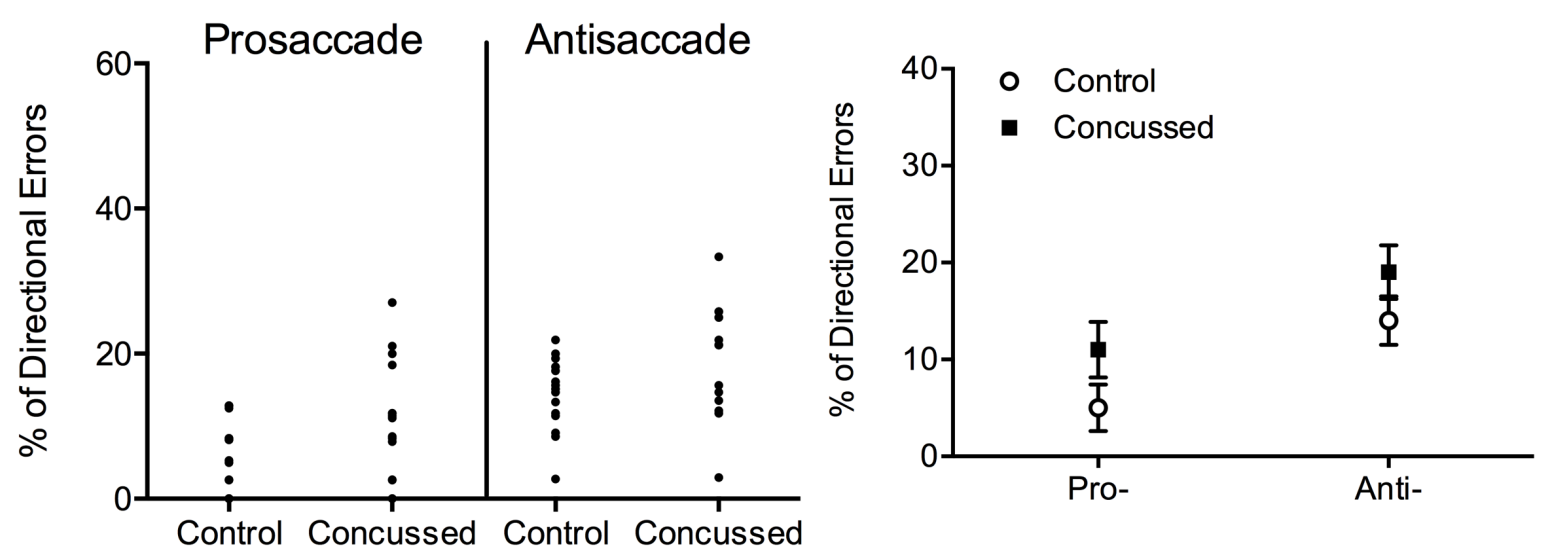

Figure 2. The large main panels show the percentage of pro- and antisaccade directional errors for individual participants in the control and concussed groups at initial (top panel) and followup (bottom panel) assessments. The smaller offset panels show group mean pro- and antisaccade 
directional errors for control and concussed groups at initial and follow-up assessments. Error bars represent $95 \%$ between-participant confidence intervals (Cumming, 2013).

Saccade gains

Saccade gains revealed main effects for group, $F(1,28)=18.13, \mathrm{p}<0.001, \eta_{\mathrm{p}}{ }^{2}=0.39$, task, $\mathrm{F}(1,28)=155.44, \mathrm{p}<0.001, \eta_{\mathrm{p}}{ }^{2}=0.84$, and a group by task interaction, $\mathrm{F}(1,28)=4.40, \mathrm{p}<0.05$, $\eta_{\mathrm{p}}{ }^{2}=0.17$. Figure 3 demonstrates that prosaccade gains for the concussed $(0.87, \mathrm{SD}=0.02)$ and control $(0.88, \mathrm{SD}=0.02)$ groups did not reliably differ $(\mathrm{t}(28)=1.64, \mathrm{p}=0.11$, whereas antisaccade gains were less for the concussed $(0.77, \mathrm{SD}=0.03)$ than the control $(0.81, \mathrm{SD}=0.03)$ group $(\mathrm{t}(28)=3.86, \mathrm{p}<0.001)$. 

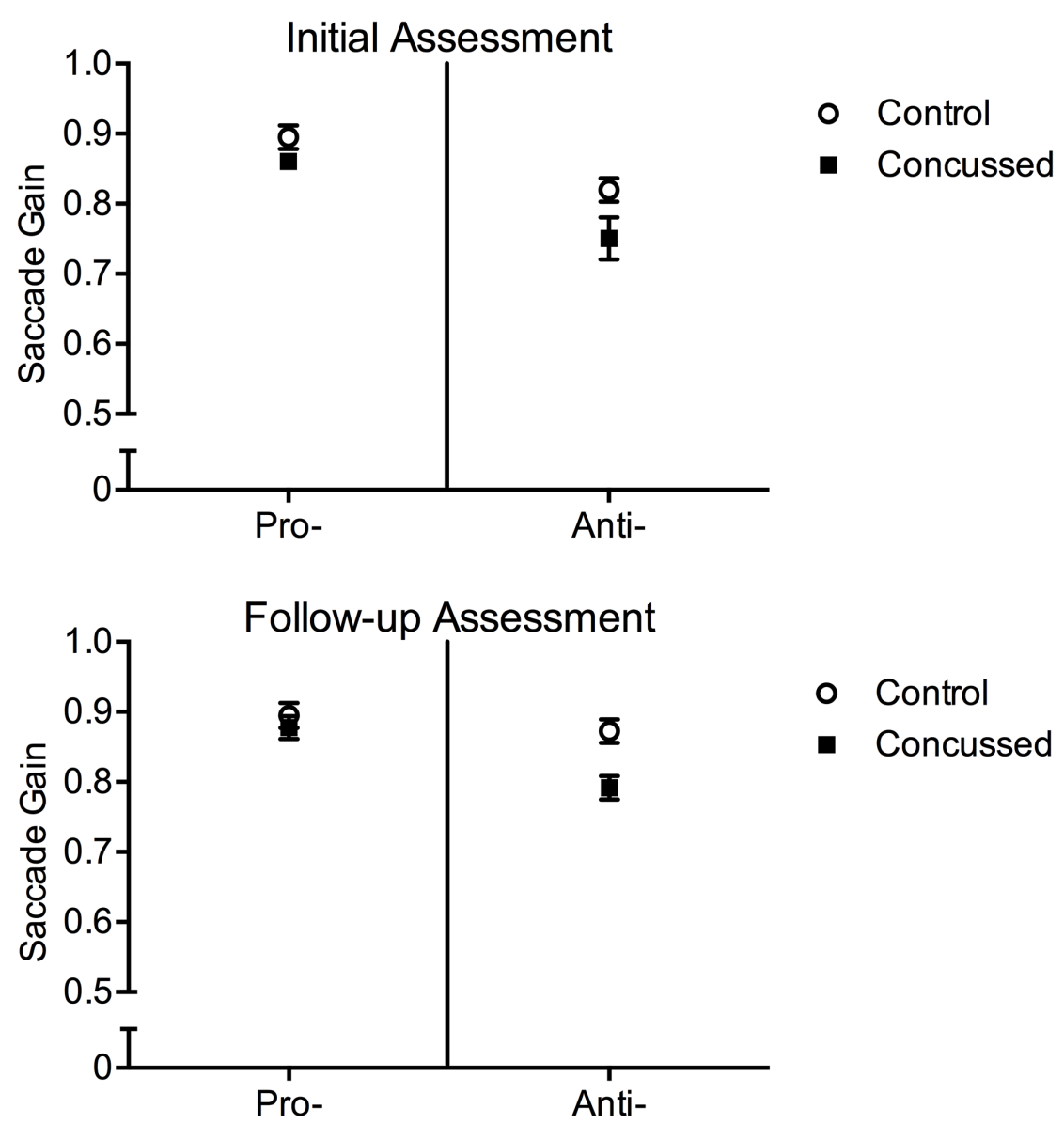

Figure 3. Mean pro- and antisaccade gains for control and concussed groups at initial and follow-up assessments. Error bars represent 95\% between-participant confidence intervals (Cumming, 2013). Note: the data shown here relate only to directionally correct pro- and antisaccades.

\section{Discussion}

The primary objectives of the present work were to determine if athletes with a sportrelated concussion exhibit a selective executive-related oculomotor deficit during the acute phase of concussion recovery, and determine whether subtle executive-related deficits persist after an athlete has been deemed safe to return to play. Importantly, I designed this study with the future goal of providing a brief assessment tool for concussion identification and recovery of function. 
Pro- and antisaccade performance metrics

Before I address my primary objectives, I first provide a general overview of the difference between pro- and antisaccades. Prosaccades yielded shorter RTs, less directional errors, and larger amplitude gains (i.e., more accurate endpoints) than antisaccades. The prosaccade findings reflect that responses with spatial overlap between stimulus and response are mediated via direct retinotopic motor maps in the superior colliculus (Wurtz \& Albano, 1980) and operate with minimal top-down control (Pierrot-Deseilligny et al., 1991). In contrast, antisaccades require the activation of an extensive frontoparietal network involved in the timeconsuming executive processes of response suppression and vector inversion (Munoz \& Everling, 2004). Moreover, the smaller antisaccade gains (i.e., less accurate endpoints) indicate that decoupling the spatial relations between stimulus and response renders motor output that is supported via visual information that is functionally distinct (i.e., relative) from the direct (i.e., absolute) visual information mediating prosaccades (Gillen \& Heath, 2014a; 2014b; Heath, Gillen, \& Weiler, 2015). These behavioural findings therefore provide a framework for examining executive and non-executive oculomotor dysfunction during the acute and later stages of concussion recovery.

\section{Prosaccades: Initial and follow-up assessment.}

The initial oculomotor assessment was completed 2-6 days following concussive injury, and most participants completed their assessment on the same day as their concussion diagnosis. Participants were therefore in the acute stage of injury recovery. The follow-up assessment was completed 14-20 days after the initial assessment and was completed only after each participant was medically cleared for a safe return to play. Results for prosaccades indicated that RT and 
amplitude gains did not reliably differ between concussed and control groups at initial or followup assessments; however, the concussed group elicited more directional errors at both time points. There are at least two possible explanations for the current pattern of findings. The first is that the increased directional errors indicates that a concussion produces a general deficit in oculomotor control. In addressing this explanation, recall that RT and amplitude gains were based on directionally correct pro- and antisaccades. Accordingly, I completed a posteriori analyses contrasting RTs and amplitude gains for pro- and antisaccades involving a directional error. Figure 4 presents data for RTs and amplitude gains and shows that values did not differ between groups at either assessment - a result suggesting that the increased number of directional errors is unrelated to a general oculomotor deficit (Barton, Pandita, Thakkar, Goff, \& Manoach, 2008). Further, if the directional errors underscored a general oculomotor deficit then I would have expected similar deficits in RT and amplitude gain values. A second possibility, is that the comparable RT and amplitude gains for concussed and control groups relates to the fact that the subcortical (i.e., superior colliculus) retinotopic projections mediating prosaccades are refractory to the mechanisms involved in a concussive injury (Smits et al., 2011), and/or that the 'simple' nature of the prosaccade task does not entail sufficient neuronal effort to detect concussive-related oculomotor deficits (Özyurt, Rutschmann, \& Greenlee, 2006). This interpretation is in line with Johnson et al.'s (2015a; b) report that prosaccade behavioural (RT and amplitude gain) and fMRI measures do not differentiate between concussed and nonconcussed athletes. In other words, convergent evidence suggests that prosaccades do not provide a reliable basis to detect oculomotor deficits in the acute or later stages of concussion recovery. 


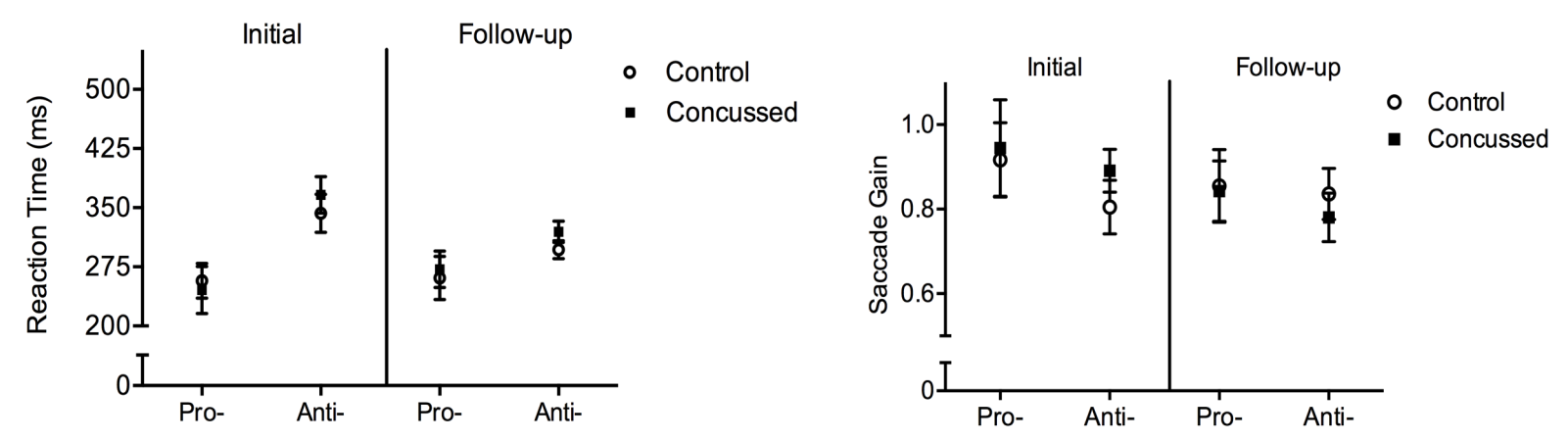

Figure 4. Mean RTs (see left panel) and amplitude gains (see right panel) for pro- and antisaccade directional error trials. The data are depicted separately for control and concussed groups at initial and follow-up assessments and error bars represent 95\% between-participant confidence intervals (Cumming, 2013).

Antisaccades: Initial and follow-up assessment.

In the present investigation, initial assessment group average antisaccade RTs for the concussed group were $93 \mathrm{~ms}$ longer than the control group. Furthermore, at the initial assessment the concussed group elicited directional errors on $34 \%$ of trials, whereas directional errors for the control group were 13\% of trials. Moreover, Figure 1 shows that the average antisaccade RT for each participant in the concussed group was longer than the average antisaccade RT for any participant in the control group, and Figure 2 shows that 12 out of 15 participants in the concussed group displayed the largest number of antisaccade directional errors. These findings were also accompanied by reduced amplitude gains in the concussed group. Therefore, and given the previously discussed prosaccade findings, I propose that athletes in the acute stage of concussion recovery exhibit a selective executive-related oculomotor dysfunction.

An interesting finding arising from my initial assessment was the magnitude of the average increase in antisaccade RT for the concussed group (i.e., $93 \mathrm{~ms}$ ). Previous work has 
reported antisaccade RT differences of 35-40 ms between individuals with prodromal Alzheimer's disease and their healthy controls (Heath et al., 2016; 2017). Similarly, Johnson et al. (2015a) observed a $40 \mathrm{~ms}$ difference between concussed and non-concussed athletes during acute recovery (i.e., $<7$ days following concussion), and Ting, Schweizer, Topolovec-Vranic, and Cusimano (2015) reported a $37 \mathrm{~ms}$ difference between persons with mTBI and their controls within the first week post-injury. I believe that the large difference in antisaccade RTs observed here might relate to the timing of my initial assessment (i.e., 2-6 days following concussion) combined with the fact that the majority of participants (14/15) completed that assessment within 2 hours of their appointment with a Fowler Kennedy clinician. Given this timing, it is possible that my oculomotor assessment exacerbated concussive-specific symptoms (i.e., headache, confusion, dizziness, nausea, fatigue, vertigo) and resulted in reduced effort and/or cognitive control (for review of symptoms and cognitive effort in concussion and mTBI see Silver, 2014). Although I did not directly measure concussive symptoms during task performance, anecdotal evidence from the concussed group indicated that most participants found the antisaccade task "really difficult" to perform.

At the follow-up assessment, antisaccade RTs did not reliably differ between the concussed group and their controls. Hence, between initial and follow-up assessment (i.e., 14-20 days) the concussed group markedly improved their antisaccade RTs. This improvement in RT could not be attributed to a speed-accuracy trade-off given that the concussed group showed a decrease in directional errors (i.e., from $34 \%$ at initial to $19 \%$ at follow-up assessment), exhibited a decrease in RT variability from initial to follow-up assessment, and produced equivalent amplitude gains at both initial and follow-up assessments. In other words, the concussed group did not simply decrease their follow-up antisaccade RTs by sacrificing accuracy; rather, the 
results evince improved executive-related oculomotor control.

Although RTs did not vary between groups at follow-up assessment, the concussed group produced more directional errors and elicited reduced amplitude gains compared to their controls. These findings agree with Johnson et al.'s (2015b) work showing that concussed individuals elicit increased directional errors and reduced amplitude gains compared to their controls at 30-days post-injury. Moreover, my results suggest that subtle executive-related deficits persist even when SCAT3 metrics and clinical evaluation indicate that an athlete may safely return to play. Moreover, the above finding underscores West and Marion's (2014) contention that: "There is no consensus or strong evidence for a single specific protocol to be followed for return to play or to school after a concussion" (p. 167). Ultimately, including an antisaccade task in a follow-up concussion assessment may serve as a reliable component to determine when an athlete may safely return to play.

\section{Study Limitations}

I recognize that the interpretations and extensions of my work may be limited to several methodological traits. First, I was unable to access the SCAT3 scores of the concussed group, and it is therefore unclear whether the severity of each participant's concussion (as determined by the SCAT3) related to the marked increase in initial assessment antisaccade RTs. Future work should examine whether there is a correlation between concussion severity and degree of antisaccade RT deficits. Second, as mentioned above, I did not measure concussive symptoms during the brief oculomotor assessment. This may represent an important issue as the difference in initial and follow-up assessment antisaccade RTs for the concussed group may directly relate to symptomology and the ability to exert appropriate executive control at the time of testing. 


\section{Conclusion}

Athletes in the acute stage of recovery from a sport-related concussion exhibited executive-related oculomotor dysfunction that negatively affected the metrics underlying the performance of antisaccades, but not prosaccades. At the follow-up assessment (i.e., 14-20 days after initial assessment) the concussed group showed a marked improvement in antisaccade RTs; however, individuals continued to show an increase in directional errors and decrease in amplitude gains compared to their healthy controls. Thus, a concussion elicits a selective executive-related oculomotor deficit that is observed during the acute and later stage of injury recovery. Further, the antisaccade task's ability to identify executive dysfunction combined with its brief administration suggest that it may provide a viable tool to diagnose and evaluate recovery of function. 


\section{References}

Barton, J.J. Pandita, M. Thakkar, K. Goff, D.C. \& Manoach, D.S. (2008) The relation between antisaccade errors, fixation stability and prosaccade errors in Schizophrenia. Exp. Brain Res., 186, 273-282.

Brainard, D.H. (1997) The psychophysics toolbox. Spat. Vis. 10, 433-436.

Brooks, J. Fos, L.A. Greve, K.W. \& Hammond, J.S. (1999) Assessment of executive function in patients with mild traumatic brain injury. J. Trauma. Inj. Inf. Crit. Care., 46, 159-163.

Brown, M., Vilis, T., \& Everling, S. (2007). Frontoparietal activation with preparation for antisaccades. J. Neurophys., 98, 1751-1762.

Bryden, M.P. (1977) Measuring handedness with questionnaires. Neuropsychologia, 15, 617624.

Catena, R.D. van Donkelaar, P. \& Chou, L.S. (2011) The effects of attention capacity on dynamic balance control following concussion. J. Neuroeng. Rehabil., 8.

Cumming, G. (2013). Understanding the New Statistics Effect Sizes, Confidence Intervals, and Meta-Analysis. London: Taylor and Francis.

Curtis, C., \& D’Esposito, M. (2003). Success and failure suppressing reflexive behavior. J. Cog. Neurosci., 15, 409-418.

Dafoe, J.M. Armstrong, I.T. \& Munoz, D.P. (2007) The influence of stimulus direction and eccentricity on pro- and anti-saccades in humans. Exp. Brain. Res., 179, 563-570. 
DeSimone, J.C. Weiler, J. Aber, G.S. \& Heath, M. (2014) The unidirectional prosaccade switchcost: Correct and error antisaccades differentially influence the planning times for subsequent prosaccades. Vis. Res., 96, 17-24.

DeSouza, J., Menon, R., \& Everling, S. (2003). Preparatory set associated with pro-saccades and anti-saccades in humans investigated with event-related fMRI. J. Neurophys., 89, 1016-1023.

Everling, S., Dorris, M., Klein, R., \& Munoz, D.P. (1999). Role of primate superior colliculus in preparation and execution of anti-saccades and pro-saccades. J. Neurosci., 19, 2740-2754.

Everling, S. \& Johnston, K. (2013) Control of the superior colliculus by the lateral prefrontal cortex. Philos. Trans. R. Soc. B. Biol. Sci., 368, 20130068.

Everling, S., Paré, M., Dorris, M., \& Munoz, D.P. (1998). Comparison of the discharge characteristics of brain stem omnipause neurons and superior colliculus fixation neurons in monkey: implications for control of fixation and saccade behavior. J. Neurophys., 79, $511-528$.

Fait, P. Swaine, B. Cantin, J.F. Leblond, J. \& McFadyen, B.J. (2013) Altered integrated locomotor and cognitive function in elite athletes 30 days postconcussion: A preliminary study. J. Head. Trauma. Rehabil., 28, 293-301.

Fischer, B. \& Weber, H. (1992) Characteristics of "anti” saccades in man. Exp. Brain Res., 89, 415-424. 
Ford, K., Goltz, H., Brown, M., \& Everling, S. (2005). Neural processes associated with antisaccade task performance investigated with event-related fMRI. Journ. Neurophys., 94, 429-440.

Gessel, L.M. Fields, S.K. Collins, C.L. Dick, R.W. \& Comstock, R.D. (2007) Concussions among United States high school and collegiate athletes. J. Athl. Train., 42, 495-503.

Gillen, C. \& Heath, M. (2014a) Perceptual averaging governs antisaccade endpoint bias. Exp. Brain Res., 232, 3201-3210.

Gillen, C. \& Heath, M. (2014b) Target frequency influences antisaccade endpoint bias: Evidence for perceptual averaging. Vis. Res., 105, 151-158.

Guitton, D., Buchtel, H., \& Douglas, R. (1985). Frontal lobe lesions in man cause difficulties in suppressing reflexive glances and in generating goal-directed saccades. Exp. Brain Res., 58, $455-472$.

Hallett, P.E. (1978) Primary and secondary saccades to goals defined by instructions. Vis. Res., 18, 1279-1296.

Harmon, K.G. Drezner, J.A. Gammons, M. Guskiewicz, K.M. Halstead, M. Herring, S.A. Kutcher, J.S. Pana, A. Putukian, M. \& Roberts, W.O. (2013) American Medical Society for Sports Medicine position statement: Concussion in sport. Br. J. Sports. Med., 47, 1526.

Heath, M. Gillen, C. \& Weiler, J. (2015) The antisaccade task: Vector inversion contributes to a statistical summary representation of target eccentricities. J. Vis., 15, 4. 
Heath, M. Shellington, E. Titheridge, S. Gill, D.P. \& Petrella, R.J. (2017) A 24-week multimodality exercise program improves executive control in older adults with a self-reported cognitive complaint: Evidence from the antisaccade task. J. Alzheimer's. Dis., 56, 167183.

Heath, M. Weiler, J. Gregory, M.A. Gill, D.P. \& Petrella, R.J. (2016) A six-month cognitivemotor and aerobic exercise program improves executive function in persons with an objective cognitive impairment: A pilot investigation using the antisaccade task. J. Alzheimer's Dis., 54, 923-931.

Heath, M. Weiler, J. Marriott, K. \& Welsh, T.N. (2011) Vector inversion diminishes the online control of antisaccades. Exp. Brain Res., 209, 117-127.

Howell, D.R. Osternig, L.R. \& Chou, L.S. (2013) Dual-task effect on gait balance control in adolescents with concussion. Arch. Phys. Med. Rehabil., 94, 1513-1520.

Johnson, B. Hallett, M. \& Slobounov, S. (2015b) Follow-up evaluation of oculomotor performance with fMRI in the subacute phase of concussion. Neurology, 85, 1163-1166.

Johnson, B. Zhang, K. Hallett, M. \& Slobounov, S. (2015a) Functional neuroimaging of acute oculomotor deficits in concussed athletes. Brain Imag. Behav., 9, 564-573.

Kaufman, L., Pratt, J., Levine, B., \& Black, S. (2012). Executive deficits detected in mild Alzheimers disease using the antisaccade task. Brain Behav., 2, 15-21.

Kraus, M.F. Little, D.M. Donnell, A.J. Reilly, J.L. Simonian, N. \& Sweeney, J.A. (2007) 
Oculomotor function in chronic traumatic brain injury. Cogn. Behav. Neurol., 20, 170178.

Langlois, J., Rutland-Brown, W., \& Wald, M. (2006). The epidemiology and impact of traumatic brain injury. Journ. Head Trauma Rehab., 21, 375-378.

Ledoux, A.A. Barrowman, N.J. Boutis, K. Davis, A. Reid, S. Sangha, G. Farion, K.J. Belanger, K. Tremblay, M.S. Yeates, K.O. DeMatteo, C. Reed, N. Zemek, R. \& Pediatric Emergency Research Canada PedCARE team (2017) Multicentre, randomized clinical trial of paediatric concussion assessment of rest and exertion (PedCARE): A study to determine when to resume physical activities following concussion in children. Br. J. Sports. Med., in press.

Lezak, M.D. (1982) The problem of assessing executive functions. Int. J. Psychol., 17, 281-297.

Macare, C., Wöstmann, N., Aichert, D., Meindl, T., \& Ettinger, U. (2014). The schizotypal brain - An fMRI antisaccade task study. Pers. Ind. Diff., 60, S45.

McCrory, P., Meeuwisse, W., Aubry, M., Cantu, B, Dvorak, J., Echemendia, R.J., ... Turner, M. (2013) Consensus statement on concussion in sport - The $4^{\text {th }}$ international conference on concussion in sport held in Zurich, November 2012. Br. J. Sports. Med., 47, 250-258.

McCrory, P., Meeuwisse, W., Dvorak, J., Aubry, M., Bailes, J., Broglio, S., ... Vos, P. (2017) Consensus statement on concussion in sport - The $5^{\text {th }}$ international conference on concussion in sport held in Berlin, October 2016. Br. J. Sports. Med., in press.

McDonald, B., Flashman, L., \& Saykin, A. (2002). Executive dysfunction following traumatic 
brain injury: Neural substrates and treatment strategies. Neurorehab., 17, 333-344.

Meaney, D.F. \& Smith, D.H. (2011) Biomechanics of concussion. Clin. Sports. Med., 30, 19-31.

Munoz, D.P. \& Everling, S. (2004) Look away: The anti-saccade task and the voluntary control of eye movement. Nat. Rev. Neurosci., 5, 218-228.

Nordström, A. Edin, B.B. Lindström, S.\& Nordström, P. (2013) Cognitive function and other risk factors for mild traumatic brain injury in young men: Nationwide cohort study. BMJ, $346, f 723$.

Norman, D.A. \& Shallice, T. (1986) Attention to action: Willed and automatic control of behavior. In Davidson, R. Schwartz, R. \& Shapiro D. (eds), Consciousness and SelfRegulation: Advances in Research and Theory IV, Plenum Press, p. 1-18.

Özyurt, J. Rutschmann, R.M. \& Greenlee, M.W. (2006) Cortical activation during memoryguided saccades. NeuroReport, 17, 1005-1009.

Pierrot-Deseilligny, C.H. Rivaud, S. Gaymard, B. \& Agid, Y. (1991) Cortical control of reflexive visually-guided saccades. Brain, 114, 1473-1485.

Preiss-Farzanegan, S.J. Chapman, B. Wong, T.M. Wu, J. \& Bazarian, J.J. (2009) The relationship between gender and postconcussion symptoms after sport-related mild traumatic brain injury. Phys. Med Rehab., 1, 245-253.

Silver, J.M. (2014) Neuropsychiatry of persistent symptoms after concussion. Psychiatr. Clin. North. Am., 37, 91-102.

Smits, M. Houston, G.C. Dippel, D.W. Wielopolski, P.A. Vernooij, M.W. Koudstaal, P.J. 
Hunink, M.G.M. \& van der Lugt, A. (2011) Microstructural brain injury in postconcussion syndrome after minor head injury. Neuroradiology, 53, 553-563.

Teel, E.F. Register-Mihalik, J.K. Blackburn, J.T. \& Guskiewicz, K.M. (2013) Balance and cognitive performance during a dual-task: Preliminary implications for use in concussion assessment. J. Sci. Med. Sport., 16, 190-194.

Thériault, M., Beaumont, L. D., Tremblay, S., Lassonde, M., \& Jolicoeur, P. (2011). Cumulative effects of concussions in athletes revealed by electrophysiological abnormalities on visual working memory. Journ. Clin. Exp. Neuropsych., 33, 30-41.

Ting, W.K.C. Schweizer, T.A. Topolovec-Vranic, J. \& Cusimano, M.D. (2015) Antisaccadic eye movements are correlated with corpus callosum white matter mean diffusivity, Stroop performance, and symptom burden in mild traumatic brain injury and concussion. Front. Neurol., 6, 271.

Wan, L. Thomas, Z. Pisipati, S. Jarvis, S.P. \& Boutros, N.N. (2017) Inhibitory deficits in prepulse inhibition, sensory gating, and antisaccade eye movement in schizotypy. Int. J. Psychophys., 114, 47-54.

Welsh, M., Pennington, B., \& Groisser, D. (1991). A normative-developmental study of executive function: A window on prefrontal function in children. Devel. Neuropsych., 7, 131-149.

Wenban-Smith, M.G. \& Findlay, J.M. (1991) Express saccades: Is there a separate population in humans? Exp. Brain. Res., 87, 218-222. 
West, T.A. \& Marion, D.W. (2014) Current recommendations for the diagnosis and treatment of concussion in sport: A comparison of three new guidelines. J. Neurotrauma, 31, 159-168.

Wurtz, R.H. \& Albano, J.E. (1980) Visual-motor function of the primate superior colliculus. Annu. Rev. Neurosci., 3, 189-226. 


\section{Appendices}

\section{Appendix A: Health Sciences Research Ethics Board Approval}

Western University Health Science Research Ethics Board HSREB Delegated Initial Approval Notice

Principal Investigator: Dr. Matthew Heath

Department \& Institution: Health Sciences\Kinesiology, Western University

Review Type: Delegated

HSREB File Number: 108431

Study Title: Using Antisaccades to Investigate Response Inhibition in the Concussed Brain

HSREB Initial Approval Date: November 14, 2016

HSREB Expiry Date: November 14, 2017

Documents Approved and/or Received for Information:

\begin{tabular}{|l|l|c|}
\hline Document Name & Comments & Version Date \\
\hline Recruitment Items & Advertisement Poster - Received 2016/08/29 & \\
\hline Western University Protocol & Received 2016/11/10 & \\
\hline Letter of Information \& Consent & & $2016 / 10 / 16$ \\
\hline
\end{tabular}

The Western University Health Science Research Ethics Board (HSREB) has reviewed and approved the above named study, as of the HSREB Initial Approval Date noted above.

HSREB approval for this study remains valid until the HSREB Expiry Date noted above, conditional to timely submission and acceptance of HSREB Continuing Ethics Review.

The Western University HSREB operates in compliance with the Tri-Council Policy Statement Ethical Conduct for Research Involving Humans (TCPS2), the International Conference on Harmonization of Technical Requirements for Registration of Pharmaceuticals for Human Use Guideline for Good Clinical Practice Practices (ICH E6 R1), the Ontario Personal Health Information Protection Act (PHIPA, 2004), Part 4 of the Natural Health Product Regulations, Health Canada Medical Device Regulations and Part C, Division 5, of the Food and Drug Regulations of Health Canada.

Members of the HSREB who are named as Investigators in research studies do not participate in discussions related to, nor vote on such studies when they are presented to the REB.

The HSREB is registered with the U.S. Department of Health \& Human Services under the IRB registration number IRB 00000940.

Ethics Officer, on behalf of Dr. Marcelo Kremenchutzky, HSREB Vice Chair Ethics Officer: Erika Basile__ Nicole Kaniki __ Grace Kelly__ Katelyn Harris__ Vikki Tran__ Karen Gopaul_ 


\section{Appendix B: Participant Letter of Information}

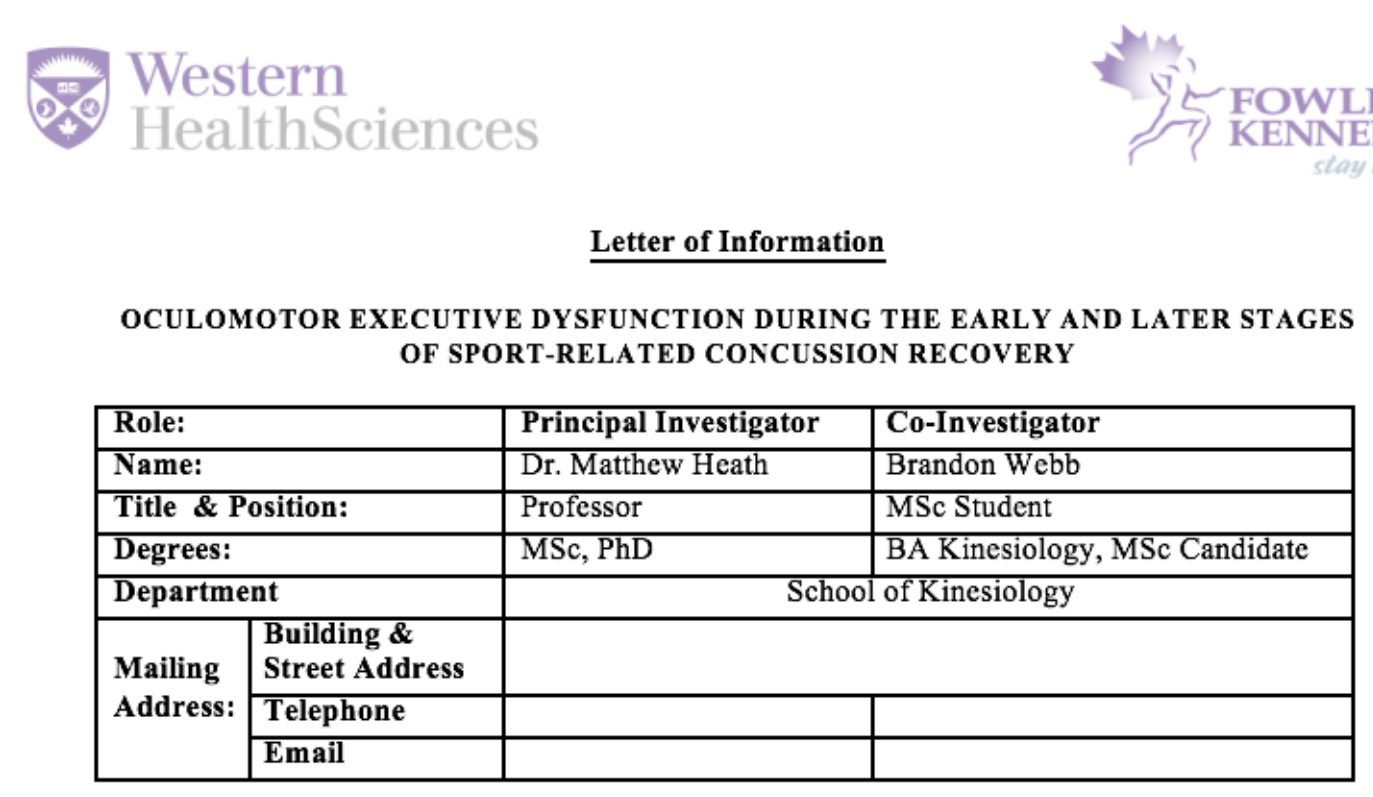

Other Co-Investigators: Lisa Fischer, MD; Dave Humphreys, MPT.

Funding Source: NSERC

\section{Invitation to Participate:}

You are being invited to take part in a study that will examine whether individuals identified as having a concussion exhibit difficulties performing top-down (i.e. cognitively challenging) eye movements (i.e. antisaccades) compared to age- and sex-matched controls without an identified concussion.

\section{Purpose of this Study:}

The purpose of this experiment is to determine whether antisaccade performance differs among those individuals with an identified concussion and their age- and sex-matched controls.

\section{Inclusion Criteria:}

Participants with an identified condition must: (1) have normal or corrected-to-normal vision, (2) self-report not having been previously diagnosed with any neurological disorder (apart from their current concussion), (3) between the ages of 18-35, and (4) received a concussion within the past 6 days as determined by a clinician from the Fowler Kennedy Sport Medicine Clinic.

Participants without an identified concussion will follow the same criterion above with the exception that they have not been previously diagnosed with a concussion. Any participant with a previous history of a concussion will be excluded.

Please take your time to read and understand all the information provided in this letter explaining why this study is being performed and what it will involve. Feel free to ask any questions if the information is unclear. 


\section{Study Procedure:}

You will be seated at a table with your head placed in a chin rest. This chin rest is padded and consists of a camera that will track your eye movements (Eye-Trac6: Applied Sciences

Laboratory, Bedford, MA. NOTE: the camera tracks the $\mathrm{x}$ and $\mathrm{y}$ coordinates of the eye and will not capture video a video of you). In front of you will be a stimulus board that will present visual stimuli (i.e. yellow LEDs) left and right of a central fixation point. You will complete two types of eye movements: (1) antisaccades (i.e., saccade mirror-symmetrical to a target) and prosaccades (i.e. saccade directly to a target). Pro- and antisaccades will be completed in separate blocks that will consist of 40 trials each. In total you will complete 80 trials and testing is anticipated to take less than 10 minutes (NOTE: when healthy individuals perform this task, a block of 150 trials is completed in less than 10 minutes). You will be asked to complete these pro- and antisaccade blocks on two separate occasions. The initial assessment will be completed less than 6 days post-concussion and the follow-up assessment will be completed 14-20 days after the initial assessment. Non-concussed participants will be tested along the same guidelines.

\section{Possible Risks and Harms:}

The only identifiable risk is mild eye fatigue. To account for this, the experimenter will ask you if you need a break in between each block, and will remind you that you can ask for a break at any time during the experiment.

\section{Possible Benefits:}

There will not be a direct benefit to you. However, this research may provide novel information on how concussions effect areas of the brain that control eye movements, and in particular, areas responsible for response suppression. Furthermore, the antisaccade task has potential to be used as a clinical and quantitative measure of an individual's concussion severity and symptom management.

\section{Voluntary Participation:}

Your participation in this study is voluntary. You may refuse to participate, refuse to answer any questions or withdraw from the study at any time with no effect. If you remove yourself from this study, you will also have the option to remove any data collected from the study analysis.

\section{Compensation:}

No monetary compensation will be given for participation in the study. However, you will be given a 'Western Mustangs' t-shirt as a gift for completing the study. You will only be given one t-shirt and it will be provided regardless of whether you complete the study protocol. You will also be reimbursed for any parking expenses via a parking voucher.

\section{Confidentiality:}

Your name, age (in years) and sex will be collected at the start of each experimental session. This is to ensure that you meet the inclusion criteria and to have your demographic data for comparison to the participant population (expressed as an age range with a mean age of participant). Your age and sex will also be used to find a healthy control that is age- and sexmatched. Your telephone number and/or email will be used to contact you in order for your return to participate in the follow-up visit (second session) of this experiment. 
Furthermore, Western University Health Sciences Research Ethics Board and Lawson Quality Assurance and Education Program may require access to study records for quality assurance purposes.

All data will be stored on a computer hard drive using subject identification numbers (this includes the identifier of what participant number you are, i.e. the date and time of data collection). Data will be stored on a password-protected computer located in a locked facility (SH 2370), and available only to the researchers identified in this project. Following publication of this study, data will be maintained only on an encrypted removable storage device and stored in a secure facility. As Lawson and LHSC requires, study records will be kept for a minimum of 15 years after completion of the experiment.

If you have any questions or concerns about the study or about being a participant, you should contact the principal investigator, Professor Matthew Heath 519-661-2111 Ext. 80498. If you have any questions about your rights as a research participant or the conduct of the study you may contact The Office of Research Ethics 519-661-3036, or email ethics@uwo.ca. 


\section{Appendix C: Participant Consent Form}

\section{Consent Form}

\section{Using Antisaccades to Investigate Response Inhibition in the Concussed Brain}

I have read the Letter of Information, have had the nature of the study explained to me, and I agree to participate. All questions have been answered to my satisfaction.

You will be given a copy of this letter of information and consent form once it has been signed.

Participant:

Name (printed):

Email:

Telephone/Mobile:

Signature: Date:

Person obtaining informed consent:

Name (printed):

Signature: Date:

Principal Investigator: Dr. Matthew Heath

Co-Investigator: Dr. Lisa Fischer

Co-Investigator: Dave Humphreys

Co-Investigator: Brandon Webb 


\section{Curriculum Vitae}

Name:

Post-secondary Education and Degrees:

Honours and Awards:

Related Work Experience

Research Presentations:
Brandon Webb

Western University

London, Ontario, Canada

Master of Science Candidate, Kinesiology

2017

Western University

London, Ontario, Canada

B.A. Kinesiology

2011-2015

Western Graduate Research Scholarship (WGRS)

Faculty of Health Science, Kinesiology

Western University

2015-2017.

Graduate Teaching Assistant

School of Kinesiology, Western University

September 2015 - April 2017

Systematic Approach to Functional Anatomy

A Physical Survey of Human Growth and Motor Development

Webb, B., Heath, M. (2016). Triggering anxiety via valence pictures does not influence change in saccade execution. Southern Ontario Motor Behaviour Symposium in partnership with the Center of Motor Control (SOMBS/CMC). 